\title{
Free share: the power of predictive science... the story of ivermectin. learn more at computational chemistry in cancer research
}

\section{Opinion}

You can search for more details but African River Blindness is a disease that only affects those in third world populations because the people there have no proper foot ware. Upon fishing, these microscopic parasitic worms get into their bodies through their feet, and yes through their bloodstream make it all the way up to their brains, and EYES causing crippling pain, blindness, and after a long spell: death. A plant extract that killed the worms on IV injection was found. The isolated key component had MULTIPLE stereocenters and NO ONE knew the correct order, at that stage, of enantiomeric centers... So, what the Japanese scientists were doing was, one by one making each possible stereoisomer (each one, yes), and comparing the NMR to that of the plant extract. Comp Chemists calculated the NMR spectra of each isomer possible in ONE DAY, and compared the predicted NMR with that of the plant extract. Ahhhh,,,, now the synthetic chemists could go to WORK! The riddle had been solved and all via the power of PREDICTIVE SCIENCE! (sure, we could also have used CD.

I think we all know that). But what did Big Pharma do with this brilliant solution for African River Blindness? Oh... the people in Africa couldn't PAY !!!!!!!!!!!!!!!! So, you know who gets that drug, now called iVermectin? American pet owners' cats and dogs for their HEART WORMS!
Volume 2 Issue 6 - 2015

Amy J Austin

Freelance Tutor for Organic Chemistry, WyzAnt Tutoring, USA

Correspondence: Amy J Austin, Freelance Tutor for Organic Chemistry, WyzAnt Tutoring, USA,

Email amy.austin@DFTdeveloper.com

Received: November 30, 2015 | Published: December 23, 2015

Join us at "Computational Chemistry for Cancer Research" group. No, we don't only talk about cancer. No, it is not only for professionals: all are welcome. We educate, learn, and teach. If you enjoyed this share, come join us.

\section{Acknowledgements}

None.

\section{Conflict of interest}

The author declares no conflict of interest. 